\title{
Electricity Theft Problem and Effects of Privatization Policies on Distribution Losses of Turkey
}

\author{
Nevzat Onat \\ Department of Electrical and Electronics Engineering, Faculty of Engineering, Manisa Celal Bayar University, \\ Campus of Şehit Prof. Dr. İlhanVarank, 45140, Manisa, Turkey \\ nevzat.onat@cbu.edu.tr \\ Received: 31 January 2018 \\ Accepted: 02 April 2018 \\ DOI: $10.18466 /$ cbayarfbe. 387054

\begin{abstract}
In the last decade, the increasing of electric energy demand in Turkey has realized as 5.5\% annually. This rapid increase in demand obliges the country to make energy investments continuously and ensure security of energy sources. In addition to energy investments, effective use of available resources is one of the most important components of sustainable development policies. In this study, technical and non-technical losses of power transmission and distribution systems and the size of these losses have been analyzed in Turkey. The effects of privatization for distribution services on such losses are presented by comparing them with analysis of statistical data. As a result of the study, it has been determined that the privatization process did not create a positive effect especially on zones using huge amount of illegal electrical energy. However, it has been determined that positive developments have occurred after the privatization at many distribution centers in terms of losses in general and the target values have been obtained. By considering that the privatization process was completed at the end of 2013, the scope and conclusions of this study can be developed further by obtaining the data for the future decade for more definite analysis.
\end{abstract}

Keywords: Electricity theft, distribution loss, privatization, electrical energy.

\section{Introduction}

It is now accepted that energy is one of the most important parameters that accelerate countries' economic development and technology production. Due to this feature which has the greatest effect on the power balances in the world, it is continuously increasing the importance of primary energy resources. Within this context, each country develops energy saving programs and carries out research and development (R\&D) and investment activities to maximize the use of local resources. The most important parameters that determine the energy production and future of the countries are listed as sustainability, productivity and equality. Each of these concepts contains arguments based on very large scales and different variables. Sustainability depends on several variables such as unit energy cost, sera gas emission, primary sources used by production technology, domestic and foreign amounts of such sources and their accessibility situations, energy transformation output, fresh water consumption and land use per unit energy, public perception etc. Efficiency is a comprehensive indicator related to different approaches applicable in every phase of production, distribution and consumption process. In general, it can be explained as the minimum energy usage as much as possible by making no concessions to personal comfort and business quality. Usually, even if it is confused with the saving concept, efficiency is a definition that covers also that concept. Security of primary sources is correlated with many strategic targets such as minimizing the foreignsource dependency, keeping of costs in compatible level and fighting with climate change. Especially in recent years, all the activities related to energy efficiency are valued in all the world countries heading towards to sustainable development targets. The equity concept is related to transmittance of energy to all citizens in the same quality because of big budgets allocated by governments for energy importation and utilization of domestic sources in the country. The injustices that may arise in terms of this concept within the country can have very serious social consequences.

Turkey's energy distribution privatization policies are subject to a number of studies in the literature. In particular, the reasons for the pause of the privatization process, which began in 2001, have been addressed in academic publications in the first years. In this process, the reform laws made by the government and the discussions between the state bodies on these laws have been analyzed [1]. It was emphasized by Erdoğdu that privatization was a crucial turning point for the sustainability of the energy distribution market of Turkey. In this article, it is stated that the presence of private companies in manipulative approaches will have very negative effects on the economy. It was also 
emphasized that senior bureaucrats should keep state interests at the highest level in the privatizations to be made. It is also described in conclusions that Turkey's energy distribution market offers significant opportunities and have very high growth potential [2].

After completion of the privatization process in 2013, impacts of this process on various parameters in the energy market of Turkey has been the subject of studies in the literature. Cetinkaya et al. focused on the rising risks in energy prices due to the risk of privatization and the negative effects of this situation will have on domestic consumers. It is emphasized that the government has made necessary checks by controlling the electricity market and tried to finance the electricity theft over consumers. Suggestions are provided that will contribute to the politics will be determined by the government [3].

Çolak et al emphasized the importance of tariff regulations in the electricity market and the decreasing of loss rate in reference [4]. Particularly they have been focused on encouraging distributed production models, cooperation between universities, companies and consumers, and efforts to increase supply quality in the establishment of smart grid structure. The additional benefits that the smart grid model will provide are also highlighted [4].

In reference [5], the effects on the sustainability indicators of the privatization of the electrical distribution system are analyzed. The electricity market transparency, the financial reliability of the distribution companies, and the quality of the electricity after privatization have also been considered in this study. The institutional structures of the distribution companies and the SWOT analysis of the whole system are also discussed in the conclusion section. The rates of the above-mentioned parameters are affected by political interference and government subsidies. The negative and advantageous developments are summarized and suggestions for a more robust structured distribution model are introduced [5].

Şirin S.M. has investigated the financial problems faced by companies after the privatization. This article focuses on the factors that affect costs, especially between 2011 and 2014. In periods when privatization is at its peak, it is determined that it has negative indicators from public opinion perception and decrease in the number of employees. In the following years, it has been stated that there is a positive effect on the increases in real expenditures and customer numbers. The negative effects that excessive fluctuations in foreign exchange rates may cause in the future have been analyzed [6].

This study presents that techno-economic size of power system transmission and distribution (T\&D) losses in Turkey. In the second section, the scope of loss concept in power systems is explained and especially, nontechnical losses are defined in detail. In the third section, the energy generation and consumption profile of Turkey is explained briefly. In the fourth section, comparisons of Turkey to the average of OEC and world in terms of power system losses are made. The effects of privatization process finalized in 2013 on the loss-illegal usage rates are examined in detail. In the last section, the conclusions and suggestions are given according to the obtained data.

\section{Materials and Methods}

One of the most important efficiency indicators of the power T\&D systems can be expressed as the transformation rate of generated electricity energy to billed consumption. The difference between these two values is called "losses" briefly. The losses size in a power system can sometimes rise to levels forcing the economies of countries and create social problems. On the other hand, reductions to be made in loss values ensure too big gains both in terms of energy amount and cost. With reduction of losses, lesser raw materials are used and so, improvement in many sustainability indicators such as sera gas emission, fresh water consumption, unit energy cost and land usage can be ensured indirectly. Besides, negative perception of the public opinion depended on reflection of illegal electricity usage or uncollectible bill fees by various means on users paying their bills regularly will be minimized. Additionally, invoicing of excessive consumption will encourage using of energy economically. All these characteristics suggest that electrical energy losses are directly or indirectly related to economic, social, political and legal aspects and are closely related to the three basic parameters mentioned in the previous section.

In Figure 1, classification of losses in the power T\&D systems is given. Essentially, power plants that convert energy using raw materials also have natural losses. However, these losses vary greatly depending on such features as the technology used and the quality of the raw materials used. In this study, an analysis was made taking into account the losses of electricity. Therefore, production losses are not included in this study. 


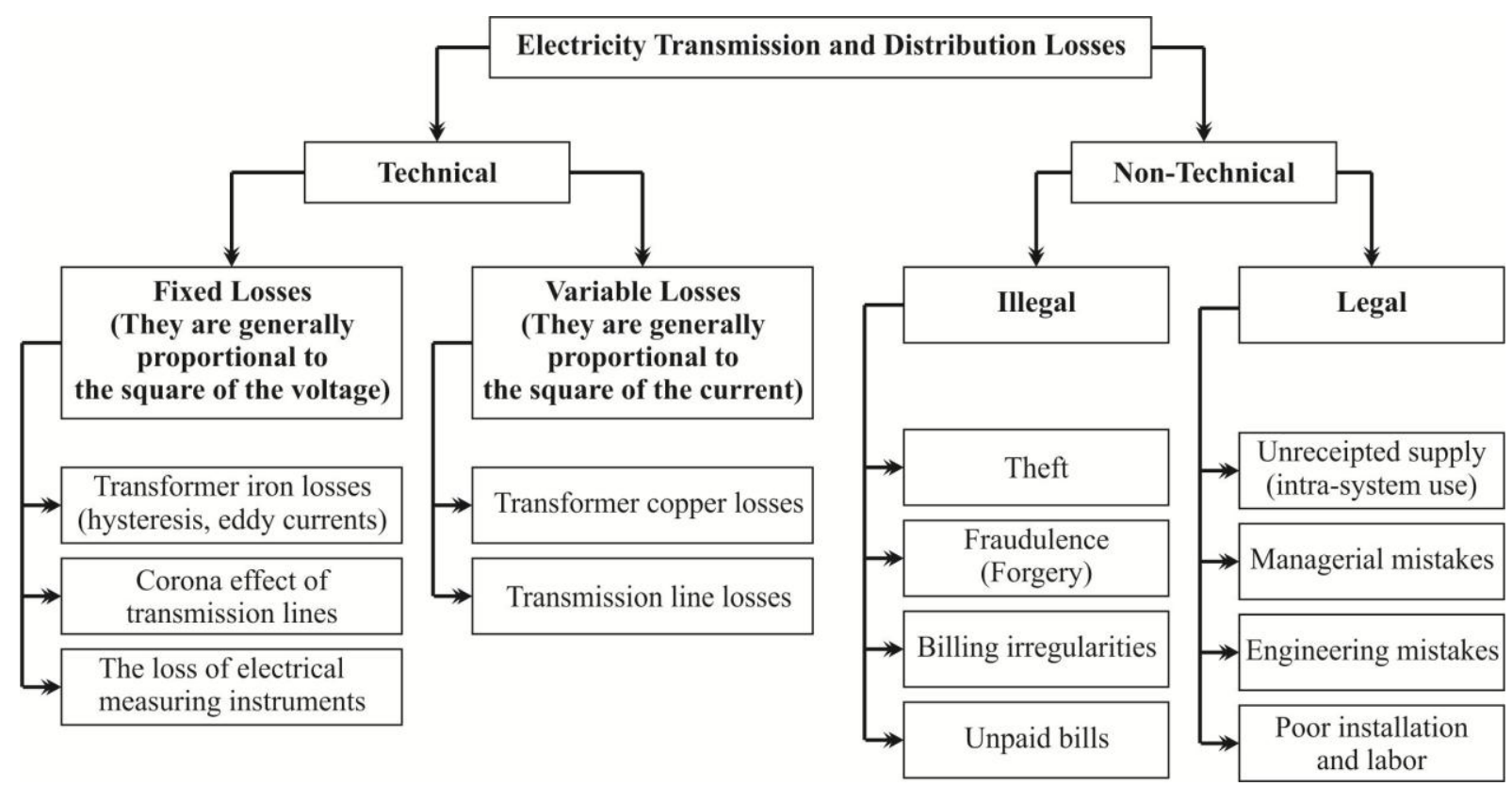

Figure 1. Classification of power system losses.

The power system losses are grouped under two categories as T\&D losses. The transmission of electrical energy is usually carried out at a high voltage (HV) level. Distribution is provided at medium (MV) and low (LV) voltage. As can be seen from this point of view, the losses of the transmission system arise mostly as technical losses, not dependent on consumers. Transmission losses, however, also have human-induced components such as technology selection, engineering calculations, and labor. However, since these components are generally not a legal criminal offense, the technical and economic dimension of transmission losses does not have a significant impact on public perception [7]. Also, statistical data show that transmission losses are usually constant and are always lower than distribution losses. The causes and dimensions of technical losses are often the main topics of the courses of electrical machinery and energy T\&D systems. This is a well-known concept that has been analyzed in detail in books and articles written in the field. Under this heading, the loss of energy measurement systems is particularly striking. As each consumer is measured with at least one meter, the losses of millions of measuring instruments reach remarkable dimensions such as $3 \%$ of total technical losses. The losses caused by factors such as read errors or malfunctions of the meters are outside these values and are mostly evaluated in the non-technical losses class [8].

\subsection{Non-Technical Losses}

Under this heading, two different energy costs arise. In Figure 1 they are classified as legal and illegal losses. Among the legal losses are the free electricity provided to schools, places of worship, some governmental institutions and persons provided free energy depending on the political and social structures of the countries, and the energy used by the power system itself (internal need power) is classified as not billed losses. The energy amount provided to these consumers can be measured, but is considered lost since the invoice is not charged. The second group of legal losses are usually losses that are based on human error and are often impossible to detect and measure. In this study, the interruptions, subscriber losses or faults that occur as a result of wrong decisions made by energy managers are called as managerial losses. Especially today, because of the distributed production systems connected by many producers simultaneously, electricity energy supply may require making instant decisions. For this reason, the consequences of administrative errors are also very large. Another human factor may also be technical errors made by responsible engineers during the design, installation and operation of the systems. These faults occur in a wide range of processes, from conductor selection to protection coordination. For example, damage can be included in this category for reasons such as unnecessary tripping or delay of a protection system when relayed in terms of selectivity. Similarly, inaccuracies in load estimations, inefficient operation resulting from the use of too large power transformers, and high losses are also in this group. Factors such as increased failure rates of old equipment and power transformers over time, not following the necessary change and revision processes and not investing can also be evaluated in this class. Bad workmanship and assembly losses are more often caused by uncontrolled processes in practice. An example of such a loss is failure in a grounding connection that is caused by improper use of proper equipment or care not to ensure proper contact. In addition, workmanship faults in the power system installation can create excessive resistance, which can cause heat losses and components that make up the system to fail more quickly. As can be 
understood from the above examples, the legal losses except the internal needs losses are totally random. For this reason, determining the technical and financial dimensions is very difficult. Typically, T\&D companies try to control parameters such as the total number of failures in the system, the duration of downtime, which is the right approach. Illegal energy losses are measurable values at precise accuracy. It is defined in four different ways in Figure-1. These concepts are briefly explained below.

\subsection{Electricity Theft}

It can be realized by the installations made by bypassing the meters which measure energy consumption. This process is often noticeable. However, it is not often that the detecting staff intervenes or even reports. The reason for this may be the sometimes violent debate between criminals and staff. However, in some cases it may be possible for the staff to feel that this is the end result of bribe taking. Further on, large companies may bribe the personnel of the electricity distribution company to make this illegal installation. Commonly used and applied methods are discussed in detail in the reference [9].

\subsection{Fraud}

Fraud in the use of electricity can be described as the illegal use of electrical equipment for purposes such as preventing billing or reducing the amount of usage. It is common to interfere with electricity meters so as not to write some of the usage amount. Plants can be installed that allow the meters to be bypassed with an invisible system and disabled when the meter is requested. These installations are usually made by non-licensed electricians. Electric shocks are also reported during these operations.

Expert electrical engineers and technicians are also able to install such installations in the face of significant bribery. Fraud is usually a method used by domestic consumers. However, rarely, large industrial enterprises can make fraud attempts. In such applications, it is very difficult to notice the situation even for very careful company personnel. For this reason, it is also difficult to distinguish between honest and fraudulent customers. Essentially, it is not possible to completely prevent the illegal use of electrical devices. It is often tried to keep it under control, by precaution such as the amount reduction measures, the awareness of consumers by various social campaigns [10].

\subsection{Billing Irregularities}

Billing errors can occur for many different reasons. In some systems, errors in the measurement of energy consumption may result in over or under charges from customers. Such mistakes are generally not illegal and can always happen. However, in some cases, bribes made by customers may result in incomplete invoicing by distribution company staff [11]. The other example is the irregularities made during payment and changing the bills of clients. For example; entering of a bill in amount of USD 285.2 in the system as amount of USD 28.52. Most of the time, the consumer do not know anything about the situation. So, the consumer makes the full payment but the personnel at the counter get earning illegally. Both illegal methods may become institutionalized in some countries and regions. Even top executives can be part of this illegal process [10]. In recent years, it has become very difficult to make such irregularities with smart grid investments made in many countries. However, this should always be seen as a risk option.

\subsection{Unpaid Bills}

Non-technical losses can also be included in the category of non-paid bills. Some people and institutions cannot pay the electricity bill for various reasons. For example, city-changers or bankrupt companies may be in this group. Also, in some countries, people with strong political or economic interests may not be sanctioned for unpaid bills. Interestingly, some citizens refuse to pay bills, arguing that electricity is a necessary service to the state. There may also be governments that tolerate such concerns as losing votes in the elections. Especially in many economically weak countries, unpaid bills is not legally defined as a theft. All of this can encourage honest consumers to use electric energy without payment.

Excessive increases in electricity energy unit prices may also increase the amount of unpaid bills and the fraud initiatives described above. Although not included in the concept of electric theft in some traditional definitions; unpaid bills should be treated as a theft. The technical value of unpaid invoices cannot be determined in terms of energy loss. It is very difficult to determine the economic dimensions for reasons such as prolonged formal procedures, amnesties brought about by political decisions, court processes [9, 10].

\subsection{The Energy Profile of Turkey}

Turkey is a country which is capable of providing electricity to every official residential consumers. Installed power capacity has doubled in the last decade (from 2006 to 2016) to $78.49 \mathrm{GW}$ from $40.56 \mathrm{GW}$. Electricity consumption per capita is around 2,669 $\mathrm{kWh} /$ year. This value is much lower than the OECD average of $8,163 \mathrm{kWh} /$ year. Similarly, the installed capacity per capita $(0.895 \mathrm{~kW})$ is well below the OECD average $(2.21 \mathrm{~kW})$. The country is in need of constant energy investment, especially in the fast-growing economy. Figure 2 shows the distribution of installed power and gross energy production for the year 2016 to the primary sources of the country. Although relatively diversified in terms of installed power, the produced 
power values indicate the foreign -dependent structure of Turkey. The most important reason for this is the low capacity utilization rates of solar, wind and hydroelectric power plants. Thus, the import dependence of natural gas is increasing. Domestic resource and production technologies are supported by the state for reducing external dependence and for sustainable development.

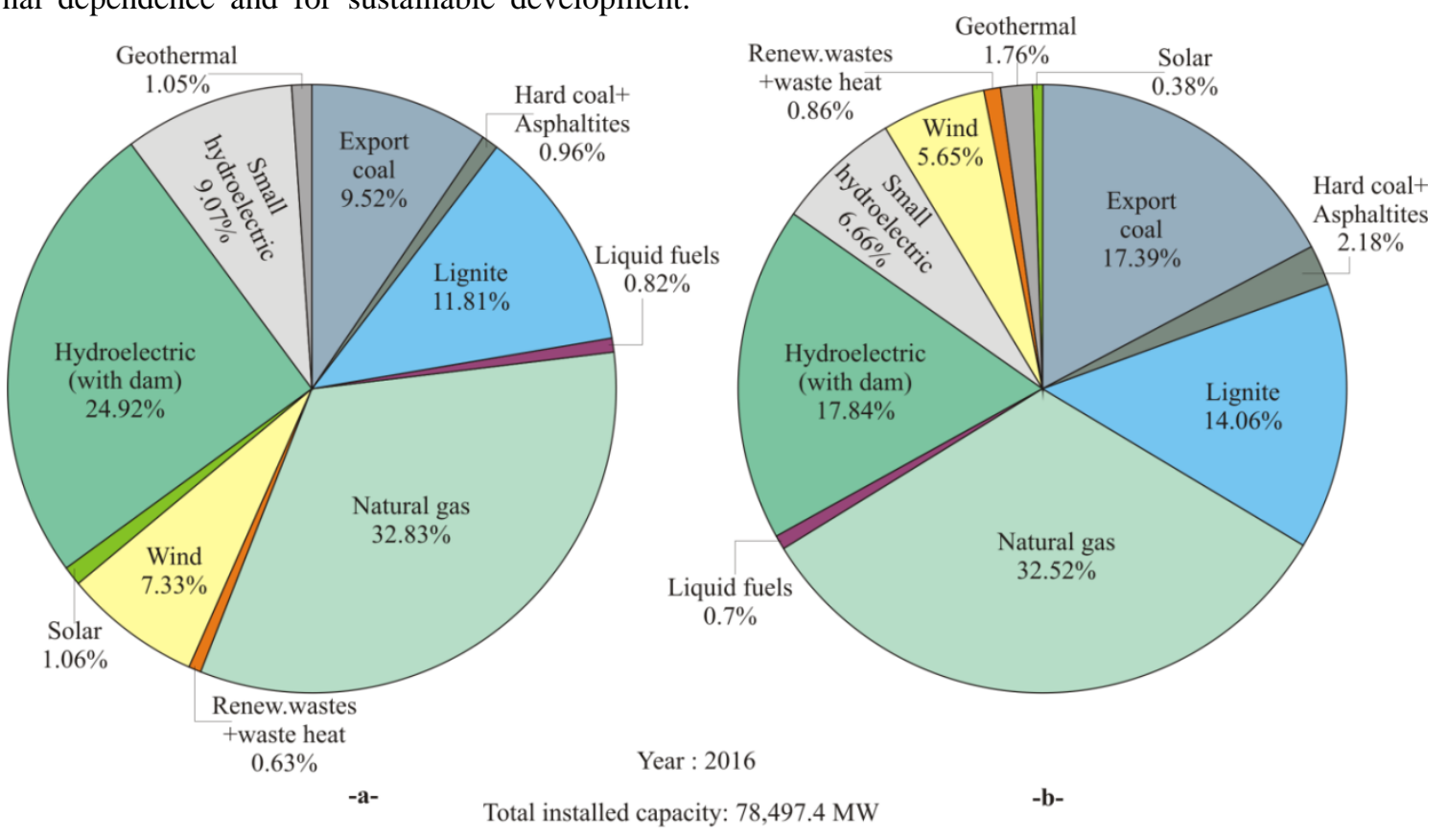

Total energy production: $274,407.7 \mathrm{GWh}$

Figure 2. Share of primary resources on a-) installed capacity and b-) total energy production in Turkey (year 2016) (Turkish Electricity, Transmission, Company, 2016).

The energy that can be converted into invoiced consumption is the efficiency indicator of the system. Turkey, in 2014, has imported about $3 \%$ of the total electrical energy. The billing rate of electricity supplied to the network, including exports, was about $82.8 \%$. In consumption, industrial facilities, public institutions and residential subscriptions were the main components. To summarize the issue, Turkey's 2014 energy efficiency diagram is given in Figure 3. It is not even theoretically possible that the efficiency of energy systems is $100 \%$. However, a total loss of $17 \%$ brings a heavy burden on the country's economy. To reduce this, the Government of Turkey is making efforts in many different areas, such as with technical specifications forced smart grid investments, energy efficiency strategy programs, privatization processes, promotional activities aimed at raising public awareness. In the studies, the potential for Turkey to increase energy efficiency for industrial consumers by $20 \%$, while domestic users is estimated to be $30 \%$ [12]. If this forecast is realized, an annual saving of 33.5 TWh of total energy consumption can be achieved, equivalent to about $13 \%$ of total production. In addition, a number of productivity-enhancing actions and targets, such as the installation of power plants using indigenous and clean primary sources, the conversion of
Private sector power plant investments are encouraged in areas such as wind, solar, geothermal and hydropower. At the same time, it is aimed that at least one nuclear power plant be commissioned by the end of 2022 to increase primary resource diversity in the country and increase energy supply quality.

industrial electric motors and drive systems, the labeling of energy consuming devices and buildings, the gradual consumption schedules and the use of electronic meters, have been included in the 2023 strategic plan [13]

Turkey, particularly by accelerating the privatization activities in the last decade, all of the energy distribution service has been transferred to the private sector. The historical chronology of the privatization process is shown in Figure 4. It can be said that the privatization activities are intensified especially in 2010 and 2013. Finally, the process was completed with the privatization of Toroslar region on 30.09.2013. Turkey is divided into 21 distribution regions. The operators of each region are serving certain provinces. In this study, the effects of the privatization process, especially on the loss-leak rates, will be taken into account. Karahan and Toptaş analyzed the effects of the privatization process on energy prices in detail. Obtained results; the positive effect on energy prices is not at the expected level. In fact, it was determined that there was a $5.9 \%$ increase, contrary to the projected $10 \%$ price decrease [14]. In addition, energy efficiency analyzes, on the whole, and distribution companies, are also subject to various studies $[12,15]$. 


\begin{tabular}{|c|l|}
\hline GENERATION FROM INSTALLED CAPACITY & \\
$251,962.8 \mathrm{GWh}$ & $96.94 \%$
\end{tabular}$\rightarrow \begin{aligned} & \text { IMPORTS } \\
& 7,593.3 \mathrm{GWh} \\
& 3.06 \%\end{aligned}$

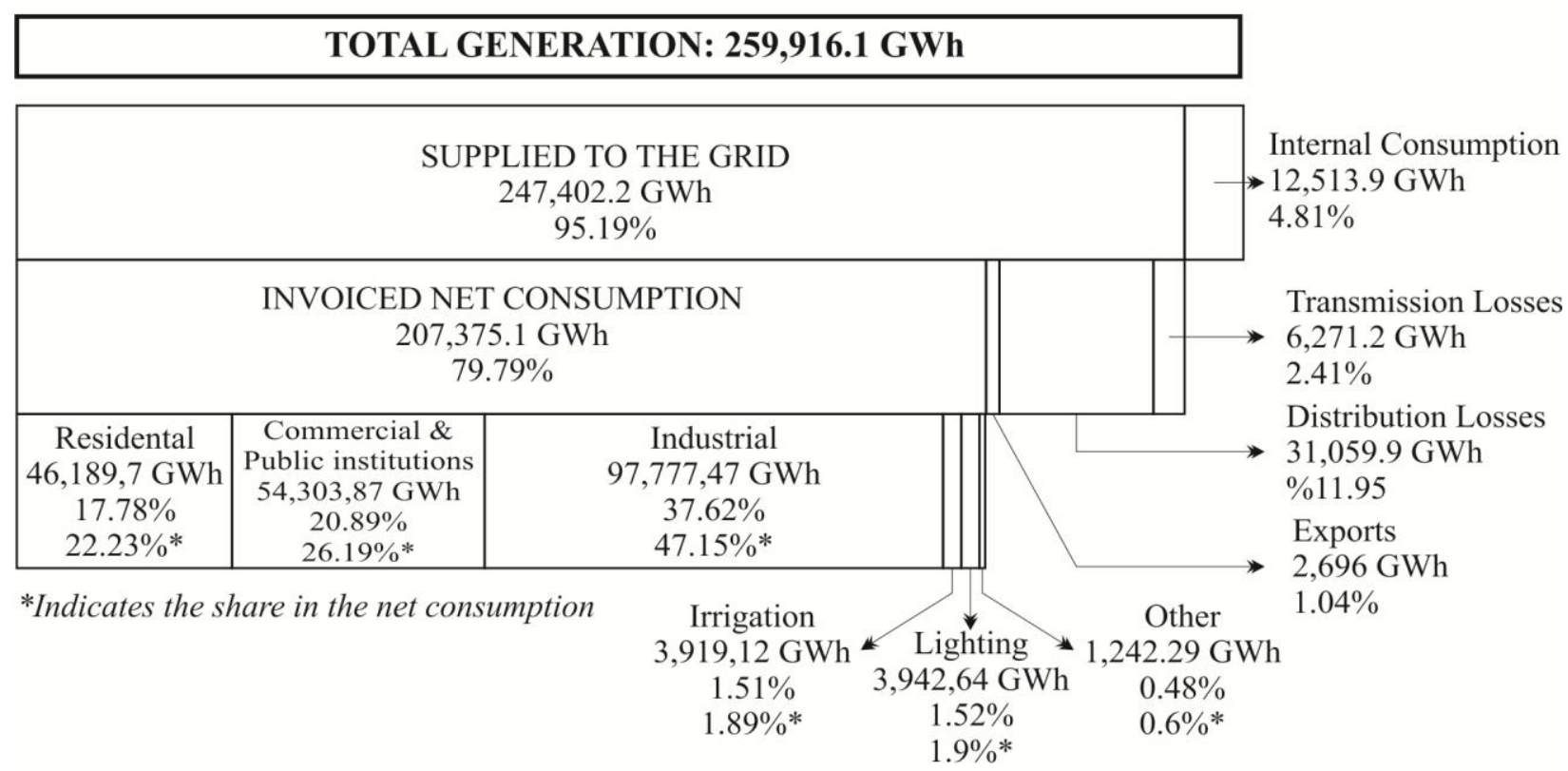

TOTAL EFFICIENCY OF NATIONAL GRID
$\frac{\text { Invoiced Net Consumption }+ \text { Exports }}{\text { Total Production }+ \text { Imports }} \times 100=82.82 \%$

Figure 3. Turkey's electricity balance sheet of $2 \overline{0} 1 \overline{4}$.

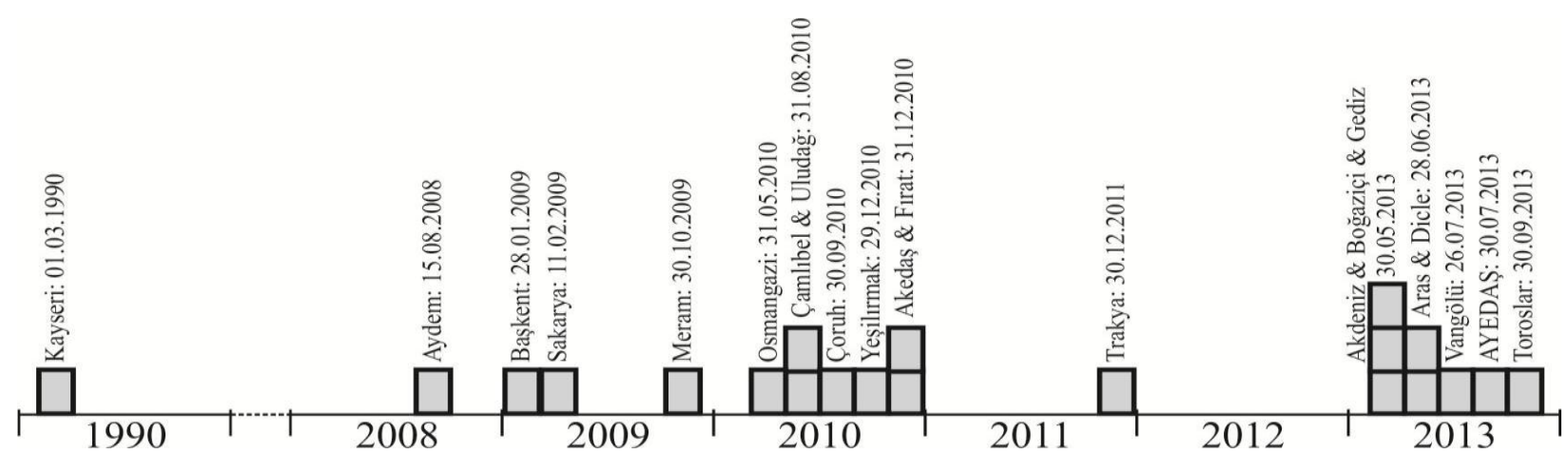

Figure 4. The process of privatization of 21 distribution regions in Turkey.

\section{Results and Discussion}

High loss-leakage rate is one of the biggest problems of Turkey's power system. In general, T\&D losses of the country are above the world and OECD averages. It has the same value as Mexico among OECD countries, following countries like Haiti, India, and Bangladesh which have more than $30 \%$ value in terms of lost leakage rate in the world. Especially compared with Western European countries $(6 \%)$ and the US $(8.7 \%)$, it can be said that the loss-leakage ratio is so high that it reduces competition power (Figure 5). This situation puts heavy burdens on the country's economy. At the same time, the negative perceptions of citizens living in regions with low rates of loss are strengthening, as the Energy Market Regulatory Board (EMRA) across the country applies the same price to all subscribers. Because, inevitably, the loss of electricity is reflected in the consumers who pay the electricity bills. In the electricity bill of a residential consumer, the lost energy cost is about $8 \%$ of the invoice amount. This value reflected on invoices is constantly being discussed in terms of public social and economic results. Figure 6 shows the change in the T\&D losses of 
the country over the past 30 years. As can be seen, the loss values which rose up to $19.4 \%$ in $1998-2001$, which are especially the effects of the economic crisis, have consistently exceeded the world average.

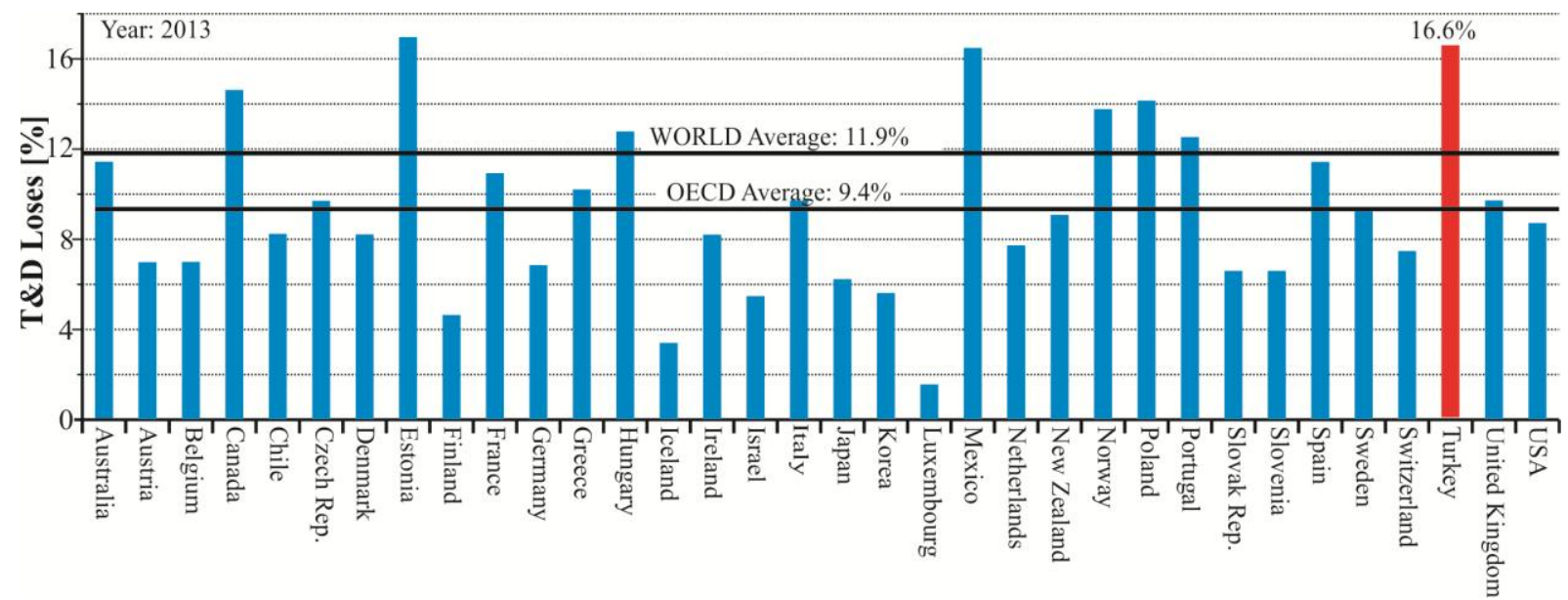

Figure 5. T\&D losses of OECD countries (Source Data: Turkish Electricity, Transmission, Company).

Especially due to the impact of the second economic crisis, it again exceeded the 15\% in 2009 and this situation continues today. The economic size of the negative table can be simply determined. The Energy Market Regulatory Board (EMRA) has set the wholesale electricity price for distribution companies to 17.75 $\mathrm{krş} / \mathrm{TL}$ (approx. 6 cents/\$) per $\mathrm{kWh}$ for the year 2016 [17]. Taking these values into consideration, the cost of approximately $31 \mathrm{TWh}$ of energy, which is the sum of only illegal distribution system losses in 2014, amounted to 5.5 billion Turkish Liras (approximately 1.87 billion $\$$ ). In the historical process, it can be said that the transmission losses are usually fixed, and proportionally decreased. However, the trend in distribution losses has generally been on the rise. Naturally, the use of illegal electricity is more concentrated in the distribution system. In addition, the proportion of administrative and engineering mistakes in distribution areas is increasing.

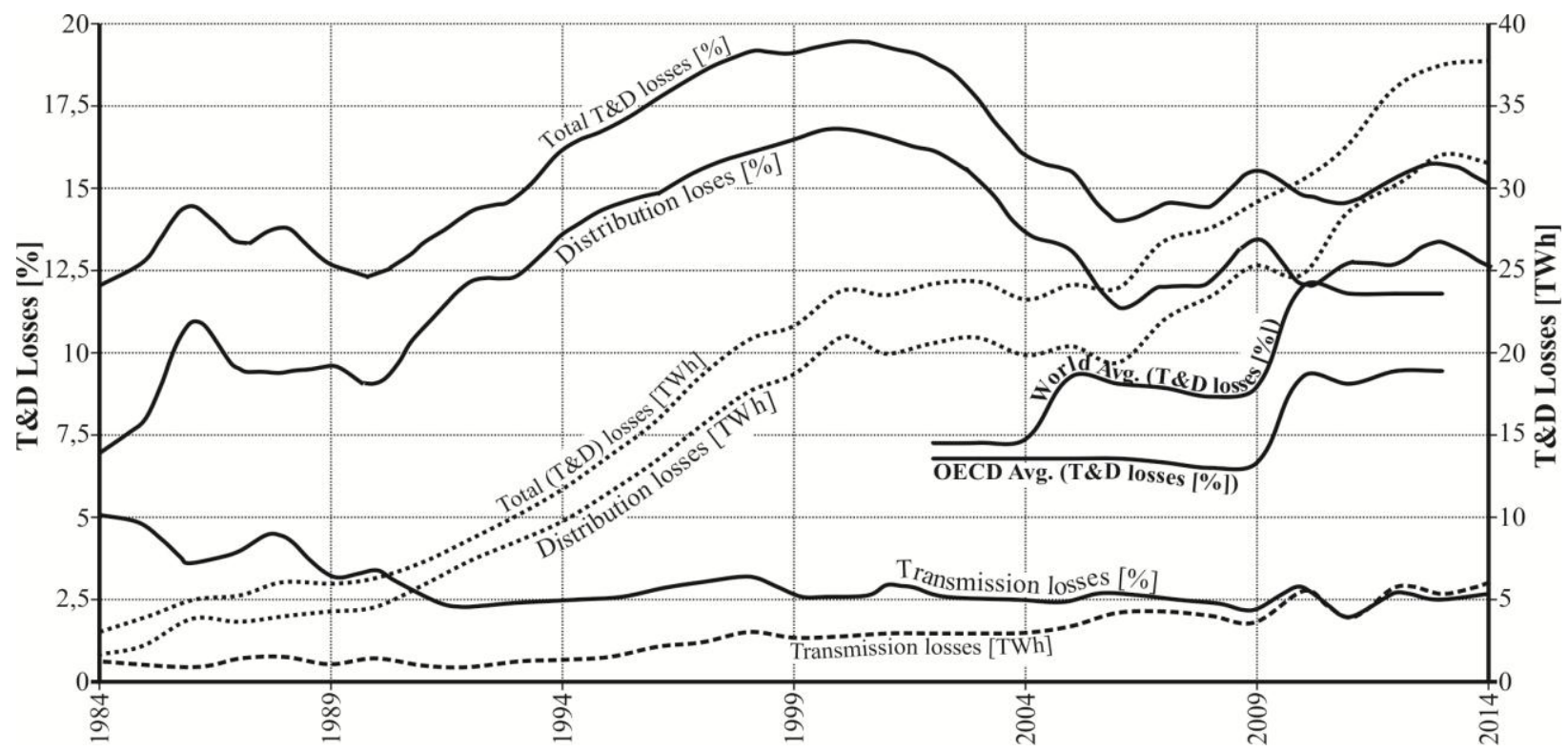

Figure 6. Graphs of T\&D Losses of Turkey. (Data Source: Reference [16]).

EMRA has started to set lost targets for every distribution region since 2011. These targets are published in the Official Gazette. In addition, sanctions have been imposed on distribution companies that cannot achieve the targeted value through legal arrangements. Target values between 2011 and 2015 were set at the EMRA meeting dated 15.12.2010 (Turkish official newspaper,
2010 , a). However, due to the fact that the target values are not realistic, the privatization process of the regions with particularly high loss rate is blocked. To overcome this bottleneck, EMRA took a second decision on 15.11.2012, raising the target values for non-privatized regions [17]. In addition, some decisions have been made to identify target loss rates and to offer advantages for 
distribution companies for high-loss regions [17]. As a result of all these regulations, it is envisaged to reduce below $10 \%$ of the lost rates in medium and long term. Generally, the reasons listed in the first section are due to high loss rates in the country. Privatized distribution companies rank the causes of technical losses as manufacturing features, poor assembly and labor, inadequate investments in parallel with the increase in demand, faulty projects and engineering (such as numerous transformers operating under nominal load and large cross-section lines etc.).

It is stated that the causes of non-technical and generally illegal losses are also technical and managerial. Technically; the shortcomings and weaknesses of measurement systems (such as easy installation of meters where meters can be intercepted, seals can be easily destroyed and imitated, and security vulnerabilities of electronic meters) are shown as the most important reasons that illegal installation can be done easily because the overhead lines in distribution systems are still not underground. In addition, delays in technological investments that include smart grid solutions, such as vulnerabilities in field scanning activities and unsubscribed consumers due to update delays, remote meter reading, energy cut / delivery are other important factors. In addition, delays in technological investments that include smart grid solutions, such as vulnerabilities in field scanning activities and unsubscribed consumers due to update delays, remote meter reading and energy cut / delivery are other important factors. The most important managerial reasons increasing the illegal losses are expressed as; loss-illegal usage targets not adapted by the senior manager to all the employees sufficiently and attempts left to the initiative to mid-level and junior level managers. Besides, because of the weakness of the follow-up of the senior management, the personnel may overlook illegal use or support it with various reasons. The reasons such as not to be able to determine or manage correctly new subscription registration procedures in the system, filing mistakes or not to be able to access fast to subscribers waiting for examination and sealing are also given. Additionally, the reasons such as not to be able to assess and finalize the illegal usage notices effectively and fast, technical incompetency of meter reading personnel and the senior management not focusing on individual development in technical meaning and ethical trends of personnel sufficiently are assessed in the managerial faults group [18]. Tasdoven et al., examining in detail Turkey's current energy management policy, have suggested that privatization and the free market economy will also make a positive contribution in terms of electricity theft [19].In this study, Turkey is divided into three regions as west, middle and east for analyzing of loss rates (Figure 7). The loss illegal usage rates of distribution companies included in each region were compared to the average of Turkey and graphics were established.

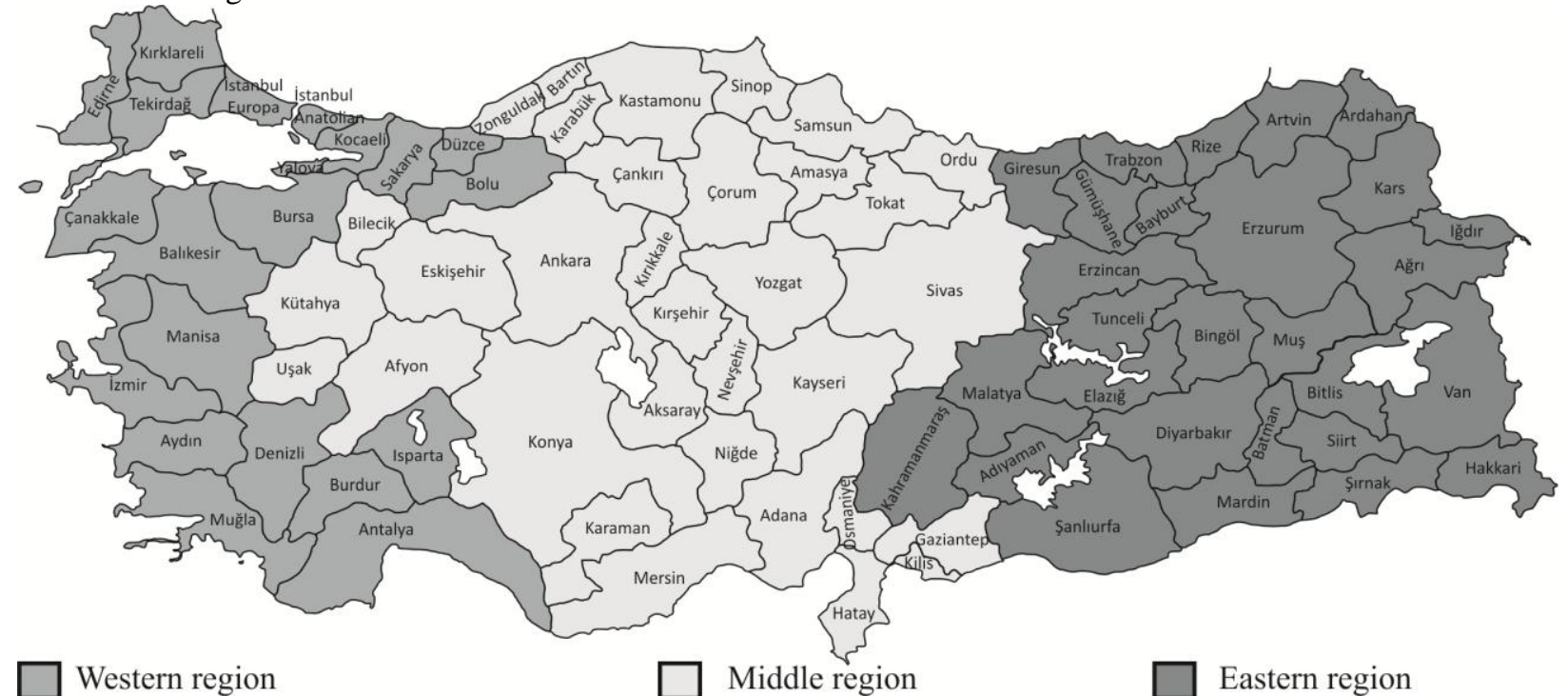

Figure 7. Three regions and provinces on the map of Turkey.

\subsection{Western Region}

In this section, Mediterranean, Aydem, Ayedaş, Boğaziçi, Gediz, Sakarya, Trakya and Uludağ distribution regions take place. The population of 20 provinces within the scope of region constitutes $45.7 \%$ of the country. This may be accepted as more developed than other regions in terms of both social-economic and population density of country. As it is seen in Figure 8, the transmission and distribution losses averages of centers within the scope of region are rather below of the average of Turkey. The loss-illegal usage rate in 2014 year was realized as $7.63 \%$. This t-rate is close to the western European values mentioned above. In particular, the Boğaziçi and Ayedaş sections cover Istanbul, the province with the highest density of population and industry in the country. The loss rate of the Boğaziçi 
region is around $9.16 \%$. The amount of energy and money as the cost of this value corresponds to Turkey's highest value. So, reducing the losses in these distribution regions or very little improvements with respect to efficiency and productivity will cause very significant results. When the privatization effects are analyzed, it is seen that especially the averages of Mediterranean, Ayedaş, Boğaziçi and Gediz distribution regions are a little above the target values determined by EMRA. The privatization process in these regions was completed in 2013 year. So, the results to be taken in future years for analyzing of the effect of loss-illegal usage rates will be more enlightening. In the distribution regions of Aydem, Sakarya, Trakya and Uludağ, where the privatization processes were completed earlier, it can be said that lower loss ratios and the target values determined are achieved successfully.

\subsection{Middle Region}

$34.9 \%$ of the country's population lives in the region covering 33 provinces. The loss rate average of 2014 year was determined as $8.42 \%$. This value is below the average of the world and OECD. The variations of the loss-illegal usage rates of the distribution centers assessed within the scope of region according to the years, Turkey average and determined target values are given in Figure 9 by comparison. The loss-illegal usage rate determined for Kayseri region $(6.92 \%$ for 2014$)$, the first privatization application of Turkey, is very below the target value (10.01\% for 2014). When considered from this point of view, positive effect of the privatization process can be seen.

However, in other regions, fluctuations can be seen anround the target values. In this section, especially in the Toroslar distribution region, the loss-illegal usage rates were realized as $13.2 \%$ in 2014 year. This value remained a bit above the $11.25 \%$ target revised by EMRA However, it is not the right approach to link the increase directly to the privatization process. Especially, as the region is a boundary neighbor with Syria, big immigrant movements experienced in recent years and big scale sheltering centers established are among the reasons of this increase. Toroslar is the latest privatized region of Turkey. For this reason, it has been expected that the determined targets would be realized within the next few years. Besides, at the end of 2014, losses had occurred just little above the target value also in the Çamlibel service region. While the target value for this region was $6.92 \%$, the loss -illegal usage rate was measured as $7.73 \%$. In general, it has not a forcing effect with respect to economic value.

\subsection{Eastern Region}

It has the region having the hardest conditions of the country geographically. The population of 28 provinces assessed in this region constitutes $19.41 \%$ of total population of the country. The region has important disadvantages in geographical conditions, climate and social-economic aspects. These negative situations take effect also in illegal losses point as in many parameters related to energy. 3 of the 5 service areas of which target values were revised by EMRA in 2012 are included in the eastern region. The general loss-illegal usage rate at the end of 2014 year was determined as $34.12 \%$. It is clearly seen that this value is too above the average of the world and OECD. Besides, it is in the level that will negatively affect the economy of country and social perception. In the Çoruh, Fırat and Göksu service areas within the scope of region, losses have occurred below the average of Turkey and around the target values. With this respect, the consumer behaviors in these service regions are similar with the Middle and Western regions.

In the Aras service area, the target loss rate determined above the average of Turkey as $21.35 \%$ was realized in the great extent as $26.21 \%$. Besides, decrease in the loss amount is observed in comparison to the period before 2013 when the privatization process was completed in the region. In Van Lake distribution area, the target value determined as $43.27 \%$ was realized as $61.02 \%$. Similarly, though 2014 target for Dicle distribution center was revised as $59.03 \%$, the total loss rate became $74.15 \%$. It can be said that these rates are parallel with the values before the privatization process. The Turkish Government aims to finalize the privatization process in the first phase for settlement of the high loss-illegal usage problem that continues in the region for years. It is predicted that the rates will be decreased gradually in future years with smart grid investments and social and cultural awareness activities in different dimensions. The fact that this region is bordered by two Middle East countries like Iraq and Syria is also an important influence. Especially in recent years, political problems in these countries, management gaps and other known reasons, the region is heavily emigrated. This makes it difficult to identify and take measures to prevent the use of lost energy in the region. So, high loss-illegal usage rates continue in the region for years. In this respect, it is also seen that privatization does not have a positive effect in the past year, but it does not result in a negative evaluation, despite various difficulties and unpredictable developments (Figure 10). 
Celal Bayar University Journal of Science

Volume 14, Issue 2, p 163-176

N. Onat
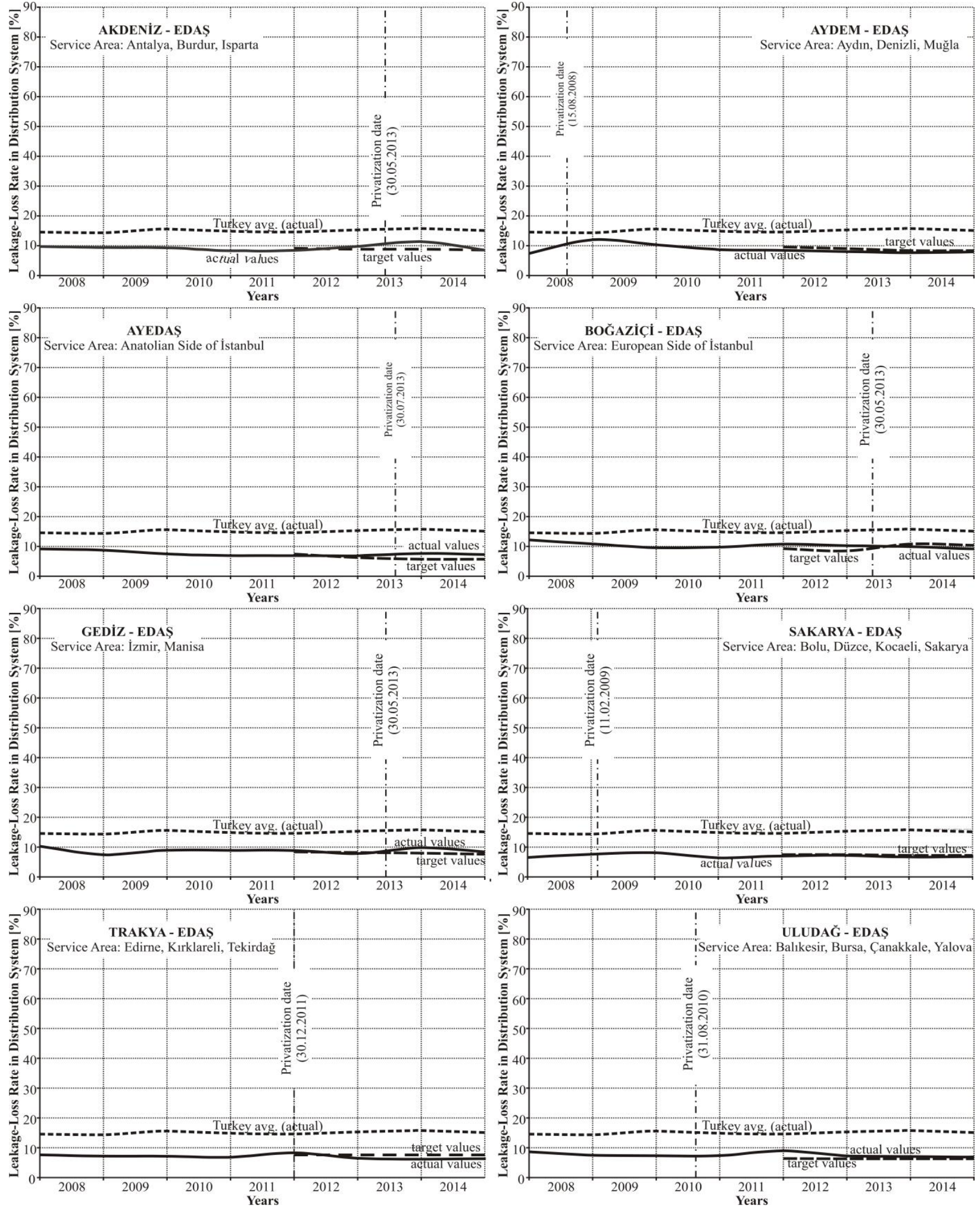

Figure 8. T\&D losses of distribution service areas in Western Region. (Data source: References [16, 17]) 
Celal Bayar University Journal of Science

Volume 14, Issue 2, p 163-176

N. Onat
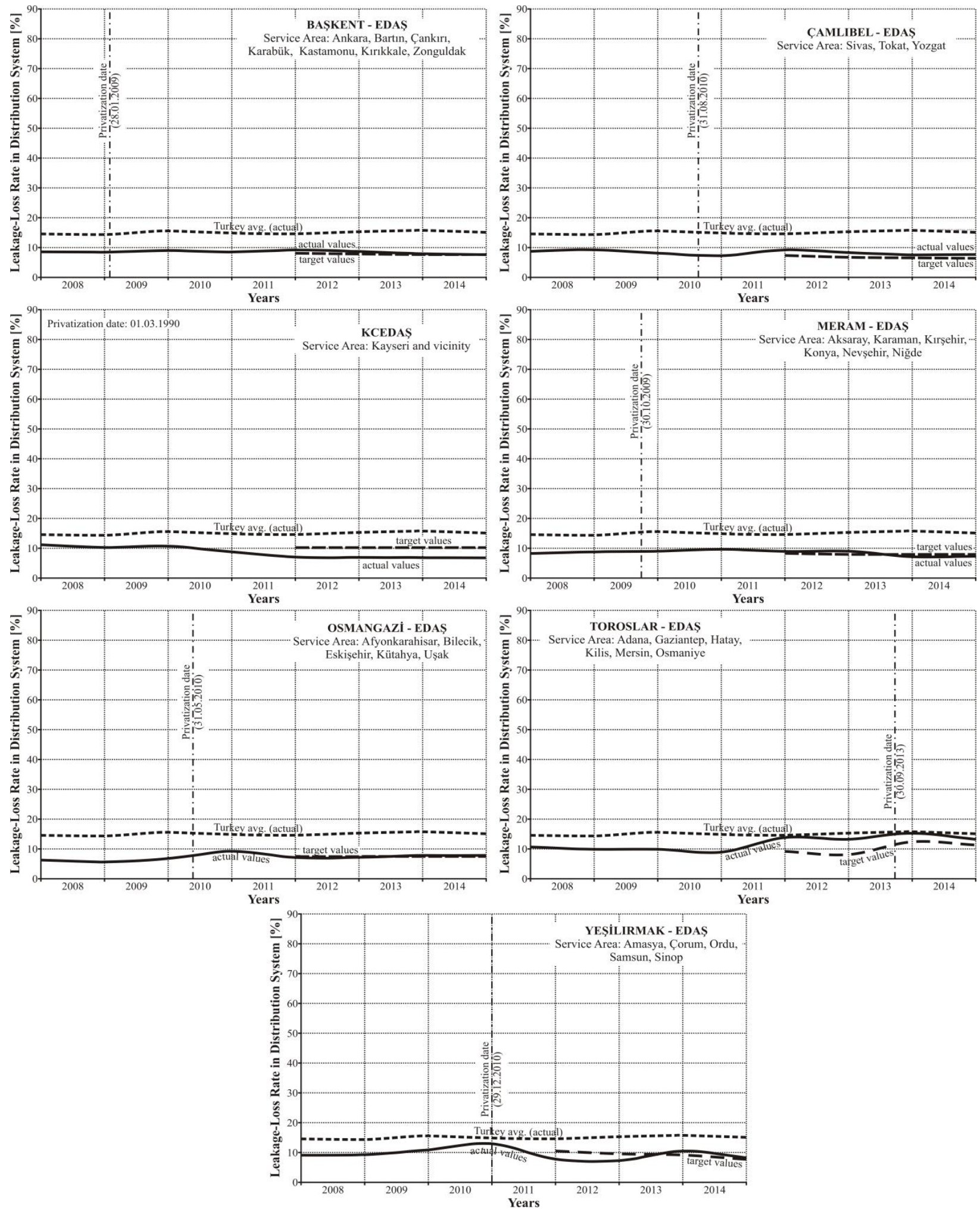

Figure 9. T\&D losses of Middle Region's distribution corporations Data source: References [16, 17]) 
Celal Bayar University Journal of Science
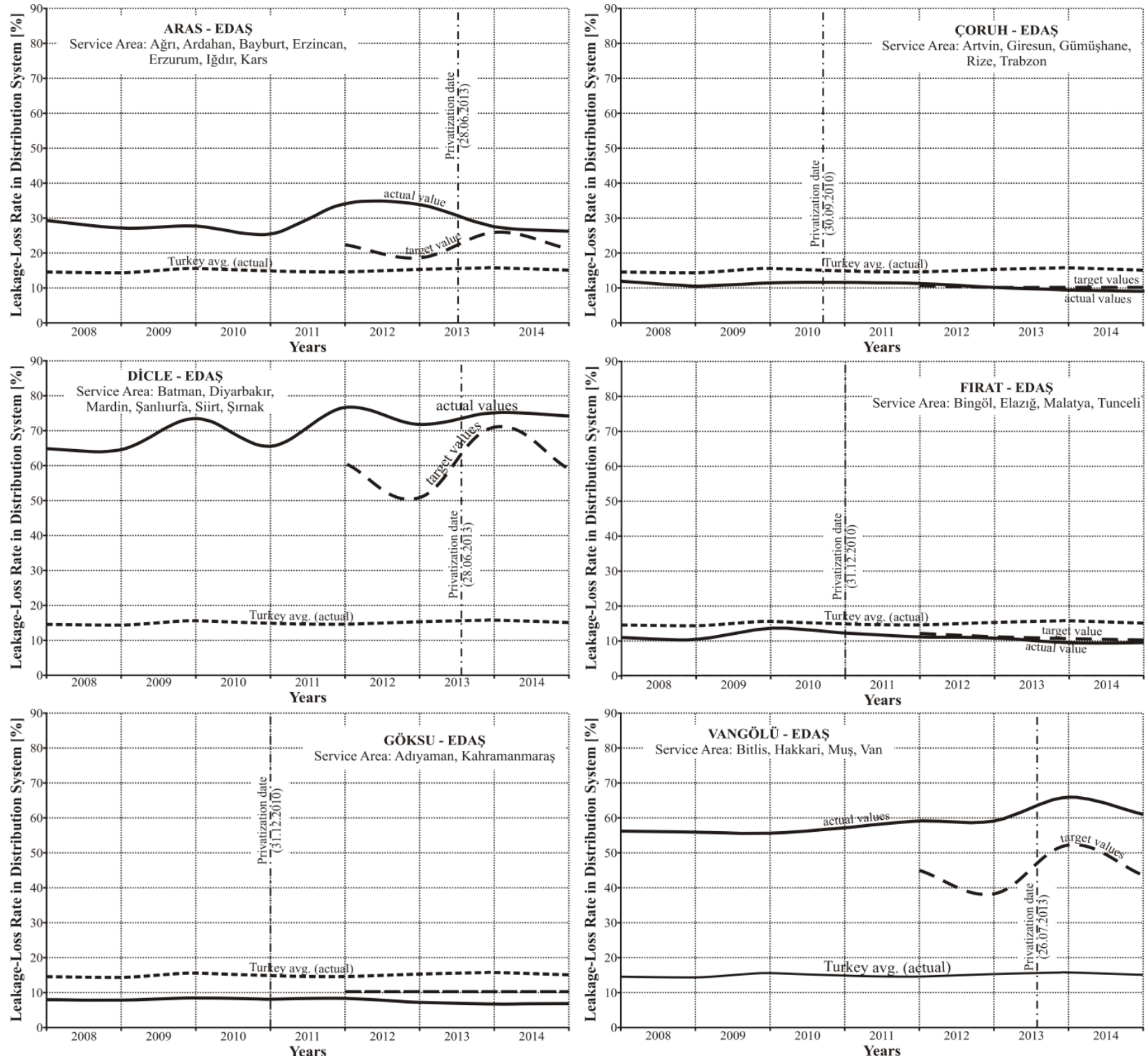

Figure 10. T\&D losses of distribution service areas in Eastern Region Data source: References [16, 17])

\section{Conclusions and Policy Implications}

There are losses in the production, transmission, distribution and consumption processes of electricity energy due to various reasons. Reducing losses that have negative effects on the overall efficiency of the system requires versatile and long-term studies. It is the first and foreseeable reason to educate managers at every stage, especially consumers, on the technical and economic benefits that can be achieved through the use of energy efficient appliances and the prevention of unnecessary consumption (energy saving). Determination of technical, managerial, political and social policies to increase the energy quality with infrastructure and superstructure investments, to accelerate the transition to smart grid model and to prevent illegal electricity usage are also very important factors. Yurtseven revealed that the most important components of electricity theft increasing in terms of social structure are the level of education, income, social capital, agricultural production and the rural population parameters. Overall, considering the population of the regions where the high theft rate, this study have reached similar conclusions. However, political problems and refugee issues experienced particularly in the Middle East region in recent years, has led to an increase in the rates of electricity theft in some regions [20].

In this study, the effects of privatization process of electricity energy distribution services, finalized by Turkey especially in 2010 and afterwards, on the transmission and distribution losses are examined. Especially, the loss-illegal usage rates realized above the averages of the world and OECD in the eastern region must be decreased to acceptable levels in a very fast manner. The Turkish Government has made great attempts on this subject both through legislative 
regulations and informative studies to take attention of the public opinion. The privatization process that is considered as the most important step in this process was finalized between years of 2010-2013. However, the high initial target values in the distribution regions with high loss-illegal usage rates slowed down the process. It is seen that the loss -illegal usage rates revised with a second decision was not realized especially in the said high rated regions. This situation rather forces the distribution companies economically. Besides, addition of the loss energy fees in the bills of consumers causes of establishment of negative public opinion perceptions. However, as the privatization process in the regions having the most negative values in terms of illegal energy usage was finalized at the end of 2013 year, statistics of future years will be followed to get efficient data and make a definite judgment. There are studies revealing that the privatization process has caused increase instead of decrease in energy unit prices. As a consequence of this article, it is determined that such a negative situation has not been experienced with respect to illegal electricity energy usage. Illegal usage rates generally follow a decreasing course. In some regions, they approximately remain constant. The additional suggestions for measures to be taken to decrease illegal usage are summarized below;

- After the privatization process, it is especially necessary to increase the support of the local government and fight against the losses. In this regard, local government elements such as governors, district governors and mayors should be informed about the issue. It should be ensured that these units support the distribution service companies in the region.

- By generalizing the collective meter applications, measuring of total consumption in definite regions

\section{References}

1. Ulusoy, A, Oguz, F, The privatization of electricity distribution in Turkey: A legal and economic analysis, Energy Policy, 2007, 35, 5021-5034.

2. Erdogdu, E, Some thoughts on the Turkish electricity distribution industry, Renewable and Sustainable Energy Reviews, 2009, 13, 1485-1494.

3. Çetinkaya, M, Başaran A.A, Bağdadioğlu, N, Electricity reform, tariff and household elasticity in Turkey, Utilities Policy, 2015, 37 $79-85$.

4. Colak, İ, Bayindir, Fulli, G, Tekin, İ, Demirtaş, K, Covrig, C.F, Smart grid opportunities and applications in Turkey, Renewable and Sustainable Energy Reviews, 2014, 33, 344-352.

5. Özbuğday, F.C, Öğ̈̈nlü, B, Alma, H, The sustainability of Turkish electricity distributors and last-resort electricity suppliers: What did transition from vertically integrated public monopoly to regulated competition with privatized and unbundled firms bring about?, Utilities Policy, 2016, 39, 50 - 67.

6. Şirin, S.M, A panel data analysis on the costs of Turkish electricity distribution companies, Energy Strategy Reviews, 2017, 18, 250 259. must be enabled from a single point. So, the data quality must be improved by monitoring from a center in very narrow regions.

- The infrastructure investments must be made on subjects like billing of consumption by reading of meters remotely and/or determination of unpaid bills. In this phase, the measures such as making of operations like cutting /delivering of energy remotely must be generalized.

- The private companies giving distribution service may develop awarding and incentive procedures for persons who contribute in decreasing of illegal usage, billing fraud or unpaid bills.

- The public may be supported with respect to both economically and contextually about works that can be done without using electricity energy and ways to determine other methods. Making of organizations to improve awareness of the public opinion more effectively and increase the government promotions given to investments within this scope will be beneficial. (For example, using of sun energy in heating of water, taking of insulation measures in heating, technical arrangements in agricultural technologies, etc).

- Determining the countries having similar problems with Turkey about fighting to illegal electricity usage, mutual knowledge and experience sharing can be ensured. For this purpose, mutual visits between academicians and public employees may be realized.

- Various activities may be organized at units like school, place of worship, etc. to take attention of the public opinion to the negation situations caused by illegal electricity usage in terms of social responsibility and ethical values.

7. Jimenez, R, Serebrisky, T, Mercado, J, Power lost sizing electricity losses in transmission and distribution systems in Latin America and the Caribbean, Press: Inter-American Development Bank Press, Washington, D.C., USA, 2014.

8. OFGEM, Office of Gas and Electricity Markets, Electricity distribution systems losses: Non-technical overview. UK, 2009.

9. Depuru, S.S.S.R, Modeling, detection, and prevention of electricity theft for enhanced performance and security of power grid. University of Toledo, (M.Sc. Thesis), Ohio, USA, 2012.

10. Smith, T.B, Electricity theft: A comparative analysis, Energy Policy, 2004, 32, 2067-2076.

11. Sharma, T, Pandey, K.K, Punia, D.K, Rao, J, Of pilferers and poachers: Combating electricity theft in India, Energy Research \& Social Science, 2016, 11, 40-52.

12. Duzgun, B, Komurgoz, G, Turkey's energy efficiency assessment: White certificates systems and their applicability in Turkey, Energy Policy, 2014, 65, 465-474. 
13. Turkish Energy Efficiency Association, 2010. Certificate of energy efficiency strategy, 2010-2023. http://www.enver.org.tr/af597e8a-65a7-438a-a05da31b22f41405.pdf (accessed 01.03.16)

14. Karahan, H, Toptas, M, The effect of power distribution privatization on electricity prices in Turkey: Has liberalization served the purpose?, Energy Policy, 2013, 63, 614-621.

15. Celen, A, Efficiency and productivity (TFP) of the Turkish electricity distribution companies: An application of two-stage (DEA\&Tobit) analysis. Energy Policy, 2013, 63, 300-310.

16. Turkish Electricity Transmission Company, 2015. Turkey's energy statistics. http://www.teias.gov.tr/ (accessed 26.02.16).
17. Turkish official newspaper, 2015. Energy Market Regulatory Authority Decision No: 6050. Issues: 29563, 27796, 28475, Ankara, Turkey.

18. INTES, Turkey Construction Industry Employers' Association,Journal of InşaatSanayii (Turkish), 2014, 144, 38-39.

19. Tasdoven, H, Fiedler, B.A, Garayev, V, Improving electricity efficiency in Turkey by addressing illegal electricity consumption: A governance approach, Energy Policy, 2012, 43, 226-234.

20. Yurtseven, Ç, The causes of electricity theft: An econometric analysis of the case of Turkey. Utilities Policy, 2015, 37, 70-78. 